\title{
Pre- and post-term growth in pre-term infants supplemented with higher-dose DHA: a randomised controlled trial
}

Carmel T. Collins ${ }^{1,2,3}$, Maria Makrides ${ }^{1,2,3 *}$, Robert A. Gibson ${ }^{1,2,4}$, Andrew J. McPhee ${ }^{5}$, Peter G. Davis ${ }^{6}$, Lex W. Doyle ${ }^{6}$, Karen Simmer ${ }^{7}$, Paul B. Colditz ${ }^{8}$, Scott Morris ${ }^{9,10}$, Thomas R. Sullivan ${ }^{11}$ and Philip Ryan ${ }^{11}$

${ }^{1}$ Women's and Children's Health Research Institute, Child Nutrition Research Centre, Flinders Medical Centre, Flinders Drive, Bedford Park, SA 5042, Australia

${ }^{2}$ Women's and Children's Health Research Institute, Child Nutrition Research Centre, Children, Youth and Women's Health Service, 72 King William Road, North Adelaide, SA 5006, Australia

${ }^{3}$ School of Paediatrics and Reproductive Health, University of Adelaide, Adelaide, SA, Australia

${ }^{4}$ Faculty of Sciences, School of Agriculture, Food and Wine, University of Adelaide, Waite Campus, PMB 1, Glen Osmond, SA 5064, Australia

${ }^{5}$ Neonatal Medicine, Children, Youth and Women's Health Service, 72 King William Road, North Adelaide, SA 5006, Australia

${ }^{6}$ Neonatal Services, Royal Women's Hospital, University of Melbourne, 20 Flemington Road, Melbourne, VIC 3052, Australia

${ }^{7}$ Neonatal Unit, School of Women's and Infant's Health, King Edward Memorial Hospital, University of Western Australia, 35 Stirling Highway, Crawley, WA 6009, Australia

${ }^{8}$ Neonatal Unit, Perinatal Research Centre, UQ Centre for Clinical Research, Royal Brisbane and Women's Hospital, The

University of Queensland, Brisbane, QLD 4029, Australia

${ }^{9}$ Centre for Perinatal Medicine, Flinders Medical Centre, Bedford Park, SA 5042, Australia

${ }^{10}$ Department of Paediatrics and Child Health, Flinders University, Bedford Park, SA, Australia

${ }^{11}$ School of Population Health and Clinical Practice, The University of Adelaide, Adelaide, SA 5005, Australia

(Received 11 May 2010 - Revised 27 September 2010 - Accepted 9 November 2010 - First published online 29 March 2011)

\section{Abstract}

The effect of the dietary $n-3$ long-chain PUFA, DHA (22:6n-3), on the growth of pre-term infants is controversial. We tested the effect of higher-dose DHA (approximately 1\% dietary fatty acids) on the growth of pre-term infants to 18 months corrected age compared with standard feeding practice $(0 \cdot 2-0 \cdot 3 \%$ DHA) in a randomised controlled trial. Infants born $<33$ weeks gestation $(n 657)$ were randomly allocated to receive breast milk and/or formula with higher DHA or standard DHA according to a concealed schedule stratified for sex and birth-weight $(<1250$ and $\geq 1250 \mathrm{~g})$. The dietary arachidonic acid content of both diets was constant at approximately $0 \cdot 4 \%$ total fatty acids. The intervention was from day 2 to 5 of life until the infant's expected date of delivery (EDD). Growth was assessed at EDD, and at 4, 12 and 18 months corrected age. There was no effect of higher DHA on weight or head circumference at any age, but infants fed higher DHA were $0.7 \mathrm{~cm}(95 \%$ CI $0.1,1.4 \mathrm{~cm} ; P=0.02)$ longer at 18 months corrected age. There was an interaction effect between treatment and birth weight strata for weight $(P=0.01)$ and length $(P=0 \cdot 04)$. Higher DHA resulted in increased length in infants born weighing $\geq 1250 \mathrm{~g}$ at 4 months corrected age and in both weight and length at 12 and 18 months corrected age. Our data show that DHA up to $1 \%$ total dietary fatty acids does not adversely affect growth.

Key words: Infants: Prematurity: Fatty acids: Growth

Growth is a marker of nutritional adequacy in pre-term infants when free of the major morbidities. Because postnatal growth failure is a common occurrence in these infants ${ }^{(1-4)}$ and is associated with increased morbidity and poorer neurodevelopmental outcomes ${ }^{(5-8)}$, ensuring adequate growth through a nutritionally complete diet is vital. The effect of dietary long-chain PUFA (LCPUFA) on the growth of pre-term infants is controversial. Some early studies have

Abbreviations: AA, arachidonic acid; DINO, docosahexaenoic acid for the improvement of neurodevelopmental outcome in pre-term infants; EDD, expected date of delivery; LCPUFA, long-chain PUFA.

*Corresponding author: M. Makrides, fax +61 88239 0267, email maria.makrides@health.sa.gov.au 
suggested that supplementing pre-term formula with the $n$-3 fatty acids DHA (22:6n-3) and EPA (20:5n-3) reduced weight and length gains ${ }^{(9-11)}$. An exploratory analysis ${ }^{(12)}$ from one of these studies ${ }^{(11)}$ showed a positive association between the concentration of erythrocyte arachidonic acid (AA, 20:4n-6) and weight and length, leading to the hypothesis that a 'balanced' dietary supply of $n-6$ and $n-3$ LCPUFA was necessary to support growth, and that AA should be added in infant formula when $n$-3 LCPUFA were present. However, subsequent studies of LCPUFA-supplemented formula that included AA and at higher concentrations than DHA have yielded inconsistent results. Studies have shown that LCPUFA supplementation had positive effects on weight $^{(13-15)}$ and length ${ }^{(13,15)}$, no effect on weight ${ }^{(16-18)}$ or length ${ }^{(14,16-18)}$ or a negative effect on weight and length ${ }^{(19)}$. Systematic reviews investigating the effects of LCPUFAsupplemented formula on the growth of pre-term infants have concluded that there are no clear effects of supplementation $^{(20,21)}$. However, it is difficult to delineate the relative effects of DHA and AA as trials with DHA alone or DHA together with AA were combined. In addition, not all of the included studies were designed to assess growth, which requires multiple assessments over time.

The Docosahexaenoic acid for the Improvement of Neurodevelopmental Outcome in pre-term infants (DINO) trial was designed to evaluate the efficacy and safety of a dose of DHA that was estimated to match in utero accretion. The unique nature of the intervention allowed us to evaluate the effect of varying DHA supplementation when AA was held constant so that the ratio of DHA:AA ranged from about 1:2 in the control group to 2:1 in the higher DHA group. The present study reports the complete growth outcomes from the DINO trial. An earlier publication has demonstrated developmental benefits of higher DHA treatment with no negative clinical outcomes ${ }^{(22)}$.

This clinical trial has been registered with the Australian and New Zealand Clinical Trial Registry. The registration number is ACTRN12606000327583, and the trial web address is anzctr.org.au

\section{Experimental methods}

The methods have been reported previously ${ }^{(22)}$. Briefly, the DINO trial was a multi-centre randomised controlled trial conducted in five Australian perinatal centres. The present study was conducted according to the guidelines laid down in the Declaration of Helsinki, and all procedures involving human subjects were approved by the local human research ethics committees of each centre (Children, Youth and Women's Health Service, North Adelaide, SA, Australia; Flinders Medical Centre, Bedford Park, SA, Australia; King Edward Memorial Hospital, Subiaco, WA, Australia; Royal Women's Hospital, Parkville, VIC, Australia; Royal Brisbane and Women's Hospital, Herston, QLD, Australia). Written informed consent was obtained from all subjects.

Infants were excluded if they had major congenital or chromosomal abnormalities; were a multiple birth where not all live births were eligible; were in other trials of fatty acid supplementation or had a lactating mother where tuna oil was contraindicated (bleeding disorders, anticoagulants).

\section{Interventions}

Lactating women allocated to the higher DHA group took six $500 \mathrm{mg}$ DHA-rich tuna oil capsules per d; if formula was required, infants were given a higher-DHA pre-term formula. Lactating women allocated to the standard DHA group took six $500 \mathrm{mg}$ placebo soya oil capsules; if formula was required, a standard pre-term infant formula was used. This strategy resulted in infants randomised to higher DHA, receiving DHA triple that of infants randomised to standard DHA with AA remaining constant between the two groups. The actual concentrations of selected fatty acids in human milk and formula are reported in Table 1.

\section{Outcomes}

Weight, length and head circumference were measured at study entry, weekly until discharge home, at the expected date of delivery (EDD), and at 4, 12 and 18 months corrected age. The primary growth measures were absolute measures at 4, 12 and 18 months corrected age. Corrected age is calculated by subtracting the number of weeks born before 40 weeks of gestation from the chronological age. We also assessed rates of increase in weight, length and head circumference between study entry and EDD. Weight, length and head circumference were taken by trained research personnel. Weight was measured to the nearest $5 \mathrm{~g}$ on calibrated electronic scales.

Table 1. Long-chain PUFA concentration in human milk and formula†‡

(Mean values and standard deviations of fatty acid as a percentage of total fat)

\begin{tabular}{|c|c|c|c|c|c|c|c|c|}
\hline & \multicolumn{4}{|c|}{ Higher DHA } & \multicolumn{4}{|c|}{ Standard DHA } \\
\hline & \multicolumn{2}{|c|}{ Human milk ( $n$ 136) } & \multicolumn{2}{|c|}{ Formula } & \multicolumn{2}{|c|}{ Human milk (n 133) } & \multicolumn{2}{|c|}{ Formula } \\
\hline & Mean & SD & Mean & SD & Mean & SD & Mean & SD \\
\hline Linoleic acid (18:2n-6) & $9 \cdot 83^{*}$ & $2 \cdot 30$ & $18 \cdot 74$ & 0.68 & $10 \cdot 4^{*}$ & 2.74 & $18 \cdot 88$ & 0.71 \\
\hline Arachidonic acid $(20: 4 n-6)$ & 0.41 & 0.08 & 0.69 & 0.29 & 0.40 & 0.08 & 0.69 & 0.22 \\
\hline$\alpha$-Linolenic acid (18:3n-3) & 0.96 & 0.33 & 1.90 & 0.62 & 1.00 & $0 \cdot 27$ & 1.92 & $0 \cdot 13$ \\
\hline $\mathrm{DHA}(22: 6 n-3)$ & $0.85^{\star \star \star}$ & 0.39 & $1 \cdot 11^{\star \star}$ & 0.29 & $0 \cdot 25^{\star \star \star}$ & $0 \cdot 13$ & $0.42^{\star \star}$ & 0.05 \\
\hline
\end{tabular}

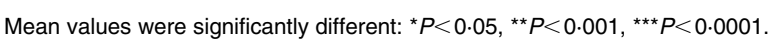

† A $5 \mathrm{ml}$ sample of breast milk was collected at the expected date of delivery appointment and immediately frozen at $-20^{\circ} \mathrm{C}$.

$\ddagger$ Infant formula and human milk fatty acids were analysed according to previously established methods ${ }^{(28)}$. 
Length was measured using a recumbent length board with one person holding the infant's head in a vertical position, with the crown of the head touching the fixed headboard and a second person extending the legs and firmly placing the movable footboard against the infant's heels, and measured to the nearest $0 \cdot 1 \mathrm{~cm}$. Head circumference was taken as the largest occipitofrontal circumference, measured to the nearest $1 \mathrm{~mm}$ using a non-stretch tape measure. Data on milk or formula type consumed were collected during the intervention period and post-treatment at 4, 12 and 18 months corrected age. Timing of introduction of solids was collected at 4 months corrected age.

\section{Randomisation}

After receiving written informed consent, mother-infant pairs were randomised through a computer-driven telephone randomisation service. Stratification occurred by centre, birth weight $(<1250$ and $\geq 1250 \mathrm{~g})$ and infant's sex. Multiple births were randomised according to the sex and birth weight of the first-born infant.

\section{Blinding}

There were four colour-coded groups: two for treatment and two for control. All capsules were similar in size, shape and colour. Formula was packaged by colour code. Parents, clinicians and all research personnel were blinded to the participant's study group.

\section{Sample size}

Sample size ( $n$ 657) was calculated to determine a clinically significant difference in the trial's primary outcome, the Mental Development Index of the Bayley Scales of Infant Development at 18 months corrected age ${ }^{(22)}$. This sample size allowed us to detect a weight difference of $395 \mathrm{~g}$ and a length difference of $0.86 \mathrm{~cm}$ with $80 \%$ power. This represents $3.6 \%$ of the weight and $1 \cdot 1 \%$ of the length at 18 months, respectively.

The study was planned to determine differences between sexes (because of the difference in the rates of growth between boys and girls) and in infants born weighing $<1250 \mathrm{~g}$, as these are the most vulnerable in terms of growth. We had $80 \%$ power to detect a $473 \mathrm{~g}$ difference in weight and a $1.3 \mathrm{~cm}$ difference in length in these subgroups.

\section{Statistics}

All infants were analysed according to the group to which they were assigned. The a priori level of significance was $P<0 \cdot 05$. Weight, length and head circumference measurements were converted to $Z$-scores (standard deviation scores) relative to the WHO Child Growth Standards ${ }^{(23)}$ using WHO software ${ }^{(24)}$. To account for dependence due to repeated measurements over time and multiple infants from the same mother, growth outcomes were analysed using linear mixed-effects models.

To assess the changes in absolute measures of weight, length and head circumference (both raw values and
$Z$-scores) over the scheduled appointments, the effects of treatment group, time (EDD, 4, 12 and 18 months corrected age) and the interaction between treatment group and time were modelled. The differences in means at each time point $(95 \%$ CI) are presented, independent of the significance of the interaction effect, as these comparisons were a priori of interest.

To assess weekly growth in weight, length and head circumference, the effects of treatment group, time (corrected age at measurement) and the interaction between treatment group and time were modelled. Analyses of weekly growth were performed for the intervention period only (enrolment to EDD), as weekly data were available.

In the models, adjustment was made for the potential confounders of sex (raw scores) and gestational age at delivery (raw and $Z$-scores). A priori subgroup analyses based on infant's sex and birth-weight strata were planned as growth varies according to sex and birth weight. The subgroup analyses were performed via factorial linear mixed-effects models to allow testing for an interaction between treatment and subgroup. All calculations were performed using SAS, version 9.2 (SAS Institute, Inc., Cary, NC, USA).

\section{Results}

The number of infants who were screened for the trial, randomly assigned to receive higher DHA or standard DHA and had growth assessments at EDD, and at 4, 12 and 18 months corrected age are shown in Fig. 1. Most trial management effort was directed at securing high follow-up rates for the primary neurodevelopmental outcome at 18 months corrected age (614 infants, $93.5 \%$ of those enrolled ${ }^{(22)}$. Growth was a secondary outcome, and where obtaining growth data proved more difficult, in particular at 12 months corrected age, this was left optional for families and is reflected in the lower rate compared with the high follow-up rates at EDD, and at 4 and 18 months corrected age. For example, weight data were available for 634 infants at EDD, this represents $97 \%$ of the infants who were originally enrolled in the trial; at 4 months corrected age, 615 infants (94\%); at 12 months corrected age, 471 infants (72\%) and at 18 months corrected age, 598 infants (91\%). Despite this, the study represents the largest growth study of DHA supplementation in pre-term infants.

The trial began on 4 April 2001, and ended with the 18 months corrected age follow-up on 21 September 2007. The demographic and clinical characteristics of the infants and their families at randomisation were comparable between the two groups (Table 2). Median duration of treatment was comparable between the higher DHA and standard DHA groups ( 9.4 (interquartile range 7.9-11.4 weeks) $v .9 .4$ (interquartile range $8 \cdot 0-11 \cdot 6$ weeks), respectively). Maternal adherence based on capsule returns was $81.1 \%$ in the higher DHA group and $81.7 \%$ in the standard DHA group $(P=0.88)$.

\section{Absolute measures of weight, length and head circumference}

There were no significant differences in weight, length or head circumference at EDD, 4 or 12 months corrected age 


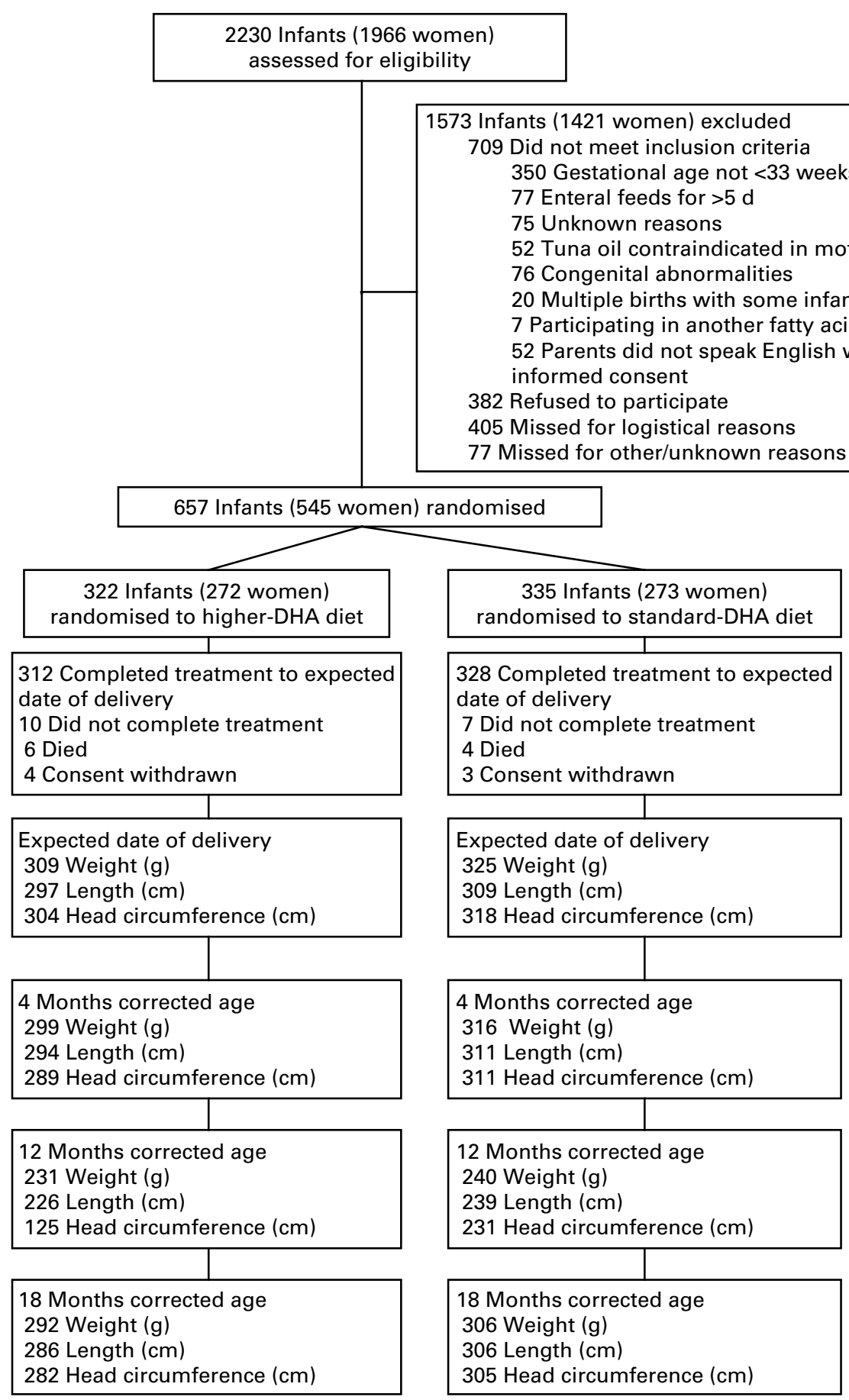

Fig. 1. Participant flow through the trial including number of infants assessed for each outcome (weight, length and head circumference) at each time point.

or in $Z$-scores (Table 3). At 18 months corrected age, the length of the higher DHA group was $0.7 \mathrm{~cm}$ greater compared with that of the standard DHA group (95\% CI $0 \cdot 1,1 \cdot 4 \mathrm{~cm}$, $P=0 \cdot 02$, adjusted for sex and gestational age; $Z=0 \cdot 28,95 \%$ CI $0.02,0.54, P=0.04$, adjusted for gestational age; Table 3 ). There were no significant differences in weight or head circumference at this time (Table 3).

A priori subgroup analyses based on the randomisation strata showed an interaction effect between dietary treatment and birth weight $(<1250$ or $\geq 1250 \mathrm{~g})$ for weight $(P=0 \cdot 01)$ and length $(P=0 \cdot 04)$. For $Z$-scores, a birth weight strata $\times$ diet interaction existed for length only $(P=0.03)$.

Infants born weighing $\geq 1250 \mathrm{~g}$ and randomised to higher DHA had a significant increase in weight at 12 and 18 months corrected age compared with infants randomised to standard DHA (adjusted difference in means 338 g, 95\% CI $89,587, P=0.01 ; 571 \mathrm{~g}, 95 \%$ CI $254,888, P=0 \cdot 0004$, respectively). At 4, 12 and 18 months corrected age, infants in the same birth-weight strata (born weighing $\geq 1250 \mathrm{~g}$ ) and randomised to higher DHA had significant increases in length 
Table 2. Baseline demographic and clinical characteristics

(Mean values, standard deviations, medians, interquartile ranges, and percentages)

\begin{tabular}{|c|c|c|c|c|}
\hline & \multicolumn{2}{|c|}{$\begin{array}{c}\text { Higher } \\
\text { DHA } \\
(n 322)\end{array}$} & \multicolumn{2}{|c|}{$\begin{array}{c}\text { Standard } \\
\text { DHA } \\
(n 335)\end{array}$} \\
\hline & $n$ & $\%$ & $n$ & $\%$ \\
\hline \multicolumn{5}{|l|}{ Recruitment hospital } \\
\hline Flinders Medical Centre & 31 & $9 \cdot 6$ & 32 & $9 \cdot 6$ \\
\hline King Edward Memorial Hospital & 65 & $20 \cdot 2$ & 57 & $17 \cdot 0$ \\
\hline Royal Brisbane and Women's Hospital & 46 & $14 \cdot 3$ & 50 & 14.9 \\
\hline Royal Women's Hospital & 61 & $18 \cdot 9$ & 63 & $18 \cdot 8$ \\
\hline Women's and Children's Hospital & 119 & $37 \cdot 0$ & 133 & $39 \cdot 7$ \\
\hline \multicolumn{5}{|l|}{ Mother's age at trial entry (years) } \\
\hline Mean & \multicolumn{2}{|c|}{$29 \cdot 9$} & \multicolumn{2}{|c|}{$30 \cdot 2$} \\
\hline SD & \multicolumn{2}{|c|}{$5 \cdot 8$} & \multicolumn{2}{|c|}{$5 \cdot 4$} \\
\hline Mother completed secondary education & 193 & 59.9 & 178 & $53 \cdot 1$ \\
\hline Father completed secondary education & 160 & $49 \cdot 7$ & 160 & $47 \cdot 8$ \\
\hline Mother smoked during pregnancy & 82 & $25 \cdot 5$ & 83 & $24 \cdot 8$ \\
\hline Previous pre-term births & 51 & $15 \cdot 8$ & 58 & $17 \cdot 4$ \\
\hline Birth by caesarean section & 220 & $68 \cdot 3$ & 234 & 69.9 \\
\hline Antenatal corticosteroids administered & 279 & $86 \cdot 6$ & 301 & $90 \cdot 1$ \\
\hline Multiple pregnancy & 98 & $30 \cdot 4$ & 123 & $36 \cdot 7$ \\
\hline \multicolumn{5}{|l|}{ Gestational age at birth (weeks) } \\
\hline Median & \multicolumn{2}{|c|}{30} & \multicolumn{2}{|c|}{30} \\
\hline Interquartile range & \multicolumn{2}{|c|}{$27-31$} & \multicolumn{2}{|c|}{$27-31$} \\
\hline Male sex & 173 & $53 \cdot 7$ & 182 & $54 \cdot 3$ \\
\hline \multicolumn{5}{|l|}{ Birth wt (g) } \\
\hline Mean & \multicolumn{2}{|c|}{1308} & \multicolumn{2}{|c|}{1307} \\
\hline SD & \multicolumn{2}{|c|}{423} & \multicolumn{2}{|c|}{415} \\
\hline Birth wt $<1250 \mathrm{~g}$ & 147 & $45 \cdot 7$ & 149 & 44.5 \\
\hline \multicolumn{5}{|l|}{ Recumbent length at birth (cm) } \\
\hline Mean & \multicolumn{2}{|c|}{$38 \cdot 2$} & \multicolumn{2}{|c|}{$38 \cdot 2$} \\
\hline SD & \multicolumn{2}{|c|}{$4 \cdot 0$} & \multicolumn{2}{|c|}{$4 \cdot 1$} \\
\hline \multicolumn{5}{|l|}{ Head circumference at birth (cm) } \\
\hline Mean & \multicolumn{2}{|c|}{$27 \cdot 2$} & \multicolumn{2}{|c|}{$27 \cdot 3$} \\
\hline SD & \multicolumn{2}{|c|}{$2 \cdot 8$} & & \\
\hline Days of partial enteral feeds pre-randomis & tion & & & \\
\hline Median & & & & \\
\hline Interquartile range & & & & \\
\hline Infant age at randomisation (d) & & & & \\
\hline Median & & & & \\
\hline Interquartile range & & & & \\
\hline Infants receiving breast milk at trial entry & 297 & $92 \cdot 2$ & 306 & $91 \cdot 3$ \\
\hline
\end{tabular}

(adjusted difference in means $0 \cdot 6 \mathrm{~cm}, 95 \% \mathrm{CI} 0 \cdot 0,1 \cdot 2, P=0 \cdot 04$ $1 \cdot 1 \mathrm{~cm}, 95 \%$ CI $0.4,1.9, P=0.004 ; 1.7 \mathrm{~cm}, 95 \%$ CI $0 \cdot 9,2.5$, $P=0.0001$, respectively; $Z=0.37,95 \%$ CI $0.09,0.65, P=0.01$; $0 \cdot 46,95 \%$ CI $0.14,0.77, P=0.004 ; 0.59,95 \%$ CI $0.26,0.91$, $P=0.0004$, respectively) compared with infants randomised to standard DHA. For infants born weighing $<1250 \mathrm{~g}$, the groups did not differ in weight or length. $Z$-scores by birthweight strata are presented in Fig. 2.

There were no interaction effects between dietary treatment and sex for weight, length or head circumference.

Rate of increase in weight, length and head circumference from enrolment to expected date of delivery (during the treatment period)

From enrolment to EDD, there were no differences between dietary treatment groups in the weekly growth rate in any of the growth indices such as weight, length and head circumference. There was a significant interaction effect $(P=0.01)$ between dietary treatment and birth-weight strata for the rate of head-circumference gain between enrolment and EDD. The head circumference of infants born weighing $<1250 \mathrm{~g}$ and randomised to higher DHA was $0.017 \mathrm{~cm} /$ week greater than that of infants randomised to standard DHA (95\% CI $0.003,0.030, P=0.02$, adjusted for gestational age and sex).

There were no interaction effects between dietary treatment and birth-weight strata for the rate of increase in weight and length. Similarly, there were no interaction effects between dietary treatment and sex for the rate of increase in weight, length or head circumference.

\section{Post-treatment diet (expected date of delivery to 18 months corrected age)}

There were no differences between randomised groups in the post-treatment source of milk at 4, 12 or 18 months corrected age (Table 4). There was no significant difference in the percentage of infants who had been introduced to solids at 4 months corrected age (59.9\% higher DHA, 53\% control; adjusted relative risk $1 \cdot 13,95 \%$ CI $0 \cdot 97,1 \cdot 33 ; P=0 \cdot 12$ ).

\section{Discussion}

In this large-scale trial, we found that infants randomised to the higher-DHA diet were longer by $0.7 \mathrm{~cm}$ at 18 months corrected age compared with infants fed according to current best practice. This effect was modest ( $28 \%$ of SD) and occurred 18 months after the intervention finished. Although it is tempting to speculate that this effect was due to random error, the direction is consistent with effects observed in some of the preplanned subgroup analyses by randomisation strata. Infants born weighing $\geq 1250 \mathrm{~g}$ responded to the intervention differently from those infants with birth weight $<1250 \mathrm{~g}$ in the post-intervention period. There were no differences in postintervention growth in infants born weighing $<1250 \mathrm{~g}$, and those born weighing $\geq 1250 \mathrm{~g}$ and randomised to higher DHA had greater mean weights at 12 and 18 months corrected age and greater mean lengths and mean length $Z$-scores at 4 , 12 and 18 months corrected age. It is unclear that why there was no effect on post-intervention growth in the lower birth-weight infants $(<1250 \mathrm{~g})$. These infants are sicker and grow less well generally.

However, during the treatment period from enrolment to EDD, infants born weighing $<1250 \mathrm{~g}$ and randomised to higher DHA had a significantly greater rate of head growth than those randomised to standard DHA. Such a small difference in the rate of head growth $(0.017 \mathrm{~cm} /$ week, $95 \% \mathrm{CI}$ $0.003,0.030 ; 0.2 \mathrm{~cm}$ over the course of average length of hospitalisation of 12 weeks) would seem unlikely to be of clinical significance. Nevertheless, it was in this group of infants where, in unadjusted analyses, a significant increase in the mental development index was found ${ }^{(22)}$. Observational studies in very pre-term infants have demonstrated an association between the rate of head circumference growth and improved neurodevelopment in childhood ${ }^{(5,25,26)}$. It is possible that even such small, yet statistically significant, increases 
Table 3. Weight, length and head circumference at expected date of delivery (EDD), and at 4, 12 and 18 months corrected age with Z-scores* $† \ddagger$ (Mean values and standard deviations, with difference of means as the treatment effect, $n$ and $95 \%$ confidence intervals)

\begin{tabular}{|c|c|c|c|c|c|c|c|c|c|c|c|}
\hline & \multirow[b]{2}{*}{$n$} & \multicolumn{2}{|c|}{ Higher DHA } & \multicolumn{2}{|c|}{ Standard DHA } & \multicolumn{2}{|c|}{ Unadjusted difference } & \multirow[b]{2}{*}{ Unadjusted $P$} & \multicolumn{2}{|c|}{ Adjusted difference $\ddagger$} & \multirow[b]{2}{*}{ Adjusted } \\
\hline & & Mean & SD & Mean & SD & Mean & $95 \% \mathrm{Cl}$ & & Mean & $95 \% \mathrm{Cl}$ & \\
\hline \multicolumn{12}{|l|}{ Weight (g) } \\
\hline EDD & $309 / 325$ & 3170 & 553 & 3120 & 533 & 28 & $-104,161$ & 0.67 & 25 & $-102,153$ & 0.70 \\
\hline Z-score & & -0.45 & $1 \cdot 15$ & -0.50 & 1.14 & 0.01 & $-0.19,0.21$ & 0.92 & 0.00 & $-0.19,0.19$ & 0.97 \\
\hline 4 months corrected age & 299/316 & 6218 & 1013 & 6203 & 1059 & -12 & $-154,130$ & 0.87 & -14 & $-151,123$ & 0.84 \\
\hline Z-score & & -0.78 & 1.34 & -0.83 & 1.37 & 0.02 & $-0.18,0.22$ & 0.87 & 0.01 & $-0.18,0.20$ & 0.92 \\
\hline 12 months corrected age & $231 / 240$ & 9317 & 1455 & 9195 & 1410 & 92 & $-119,304$ & 0.39 & 78 & $-127,284$ & 0.45 \\
\hline Z-score & & -0.13 & 1.33 & -0.27 & 1.36 & 0.10 & $-0.12,0.33$ & 0.37 & 0.09 & $-0.13,0.31$ & 0.42 \\
\hline 18 months corrected age & 292/306 & 11029 & 1764 & 10775 & 1520 & 176 & $-89,442$ & 0.19 & 162 & $-96,419$ & 0.22 \\
\hline Z-score & & 0.13 & 1.26 & -0.06 & 1.21 & 0.14 & $-0.09,0.38$ & 0.23 & 0.13 & $-0.09,0.36$ & 0.25 \\
\hline \multicolumn{12}{|l|}{ Length $(\mathrm{cm})$} \\
\hline EDD & 297/309 & 48.4 & $2 \cdot 9$ & $48 \cdot 3$ & $2 \cdot 9$ & 0.2 & $-0.4,0.7$ & 0.56 & $0 \cdot 1$ & $-0.4,0.6$ & 0.60 \\
\hline Z-score & & -0.88 & 1.51 & -0.86 & 1.51 & 0.02 & $-0.22,0.25$ & 0.90 & 0.01 & $-0.22,0.23$ & 0.96 \\
\hline 4 months corrected age & $294 / 311$ & 61.3 & 3.2 & $61 \cdot 2$ & 3.4 & 0.1 & $-0.4,0.7$ & 0.60 & 0.1 & $-0.4,0.6$ & 0.60 \\
\hline$Z$-score & & -0.87 & 1.46 & -0.95 & 1.55 & 0.08 & $-0.15,0.32$ & 0.49 & 0.08 & $-0.15,0.31$ & 0.50 \\
\hline 12 months corrected age & $226 / 239$ & 74.3 & 3.6 & 74.1 & 3.7 & 0.3 & $-0.3,1.0$ & 0.27 & 0.3 & $-0.3,0.9$ & 0.27 \\
\hline Z-score & & -0.27 & 1.43 & -0.40 & 1.50 & 0.16 & $-0.11,0.42$ & 0.24 & 0.15 & $-0.10,0.41$ & 0.24 \\
\hline 18 months corrected age & $286 / 306$ & 81.9 & 4.0 & $81 \cdot 2$ & 3.9 & 0.8 & $0.1,1.4$ & 0.02 & 0.7 & $0.1,1.4$ & 0.02 \\
\hline Z-score & & 0.20 & 1.35 & -0.10 & 1.33 & 0.28 & $0.01,0.55$ & 0.04 & 0.28 & $0.02,0.54$ & 0.04 \\
\hline \multicolumn{12}{|l|}{ Head circumference $(\mathrm{cm})$} \\
\hline EDD & $304 / 318$ & $35 \cdot 3$ & 1.6 & $35 \cdot 2$ & 1.6 & 0.005 & $-0.3,0.3$ & 0.97 & 0.004 & $-0.2,0.3$ & 0.98 \\
\hline Z-score & & 0.66 & 1.22 & 0.67 & $1 \cdot 28$ & -0.04 & $-0.25,0.16$ & 0.67 & -0.05 & $-0.24,0.15$ & 0.64 \\
\hline 4 months corrected age & 289/312 & 41.6 & 1.7 & 41.8 & $1 \cdot 7$ & -0.2 & $-0.4,0.1$ & 0.20 & -0.2 & $-0.4,0.1$ & 0.17 \\
\hline Z-score & & 0.38 & 1.31 & 0.48 & 1.26 & -0.12 & $-0.33,0.08$ & 0.24 & -0.12 & $-0.32,0.07$ & 0.22 \\
\hline 12 months corrected age & $225 / 231$ & $46 \cdot 1$ & $1 \cdot 8$ & $46 \cdot 2$ & $1 \cdot 8$ & -0.1 & $-0.4,0.2$ & 0.48 & -0.1 & $-0.4,0.2$ & 0.45 \\
\hline Z-score & & 0.44 & 1.29 & 0.45 & 1.32 & -0.05 & $-0.28,0.17$ & 0.64 & -0.06 & $-0.28,0.16$ & 0.61 \\
\hline 18 months corrected age & $282 / 305$ & $47 \cdot 8$ & 1.8 & $47 \cdot 8$ & $1 \cdot 7$ & -0.05 & $-0.4,0.3$ & 0.76 & -0.1 & $-0.4,0.3$ & 0.74 \\
\hline Z-score & & 0.66 & 1.26 & 0.62 & $1 \cdot 21$ & -0.02 & $-0.25,0.21$ & 0.86 & -0.02 & $-0.25,0.21$ & 0.84 \\
\hline
\end{tabular}

* Reference data for calculating $Z$-scores according to the WHO Child Growth Standards ${ }^{(23)}$

$\dagger P$ values for treatment group-by-time interactions were as follows: weight $(0.40$ unadjusted, 0.44 adjusted), weight $Z$-score $(0.54$ unadjusted, 0.56 adjusted), length $(0.11$ unadjusted, 0.13 adjusted), length $Z$-score $(0.11$ unadjusted, 0.09 adjusted), head circumference ( 0.29 unadjusted, 0.27 adjusted) and head circumference $Z$-score $(0.62$ unadjusted, 0.63 adjusted).

‡ Raw scores adjusted for gestational age and sex; $Z$-scores adjusted for gestational age. 

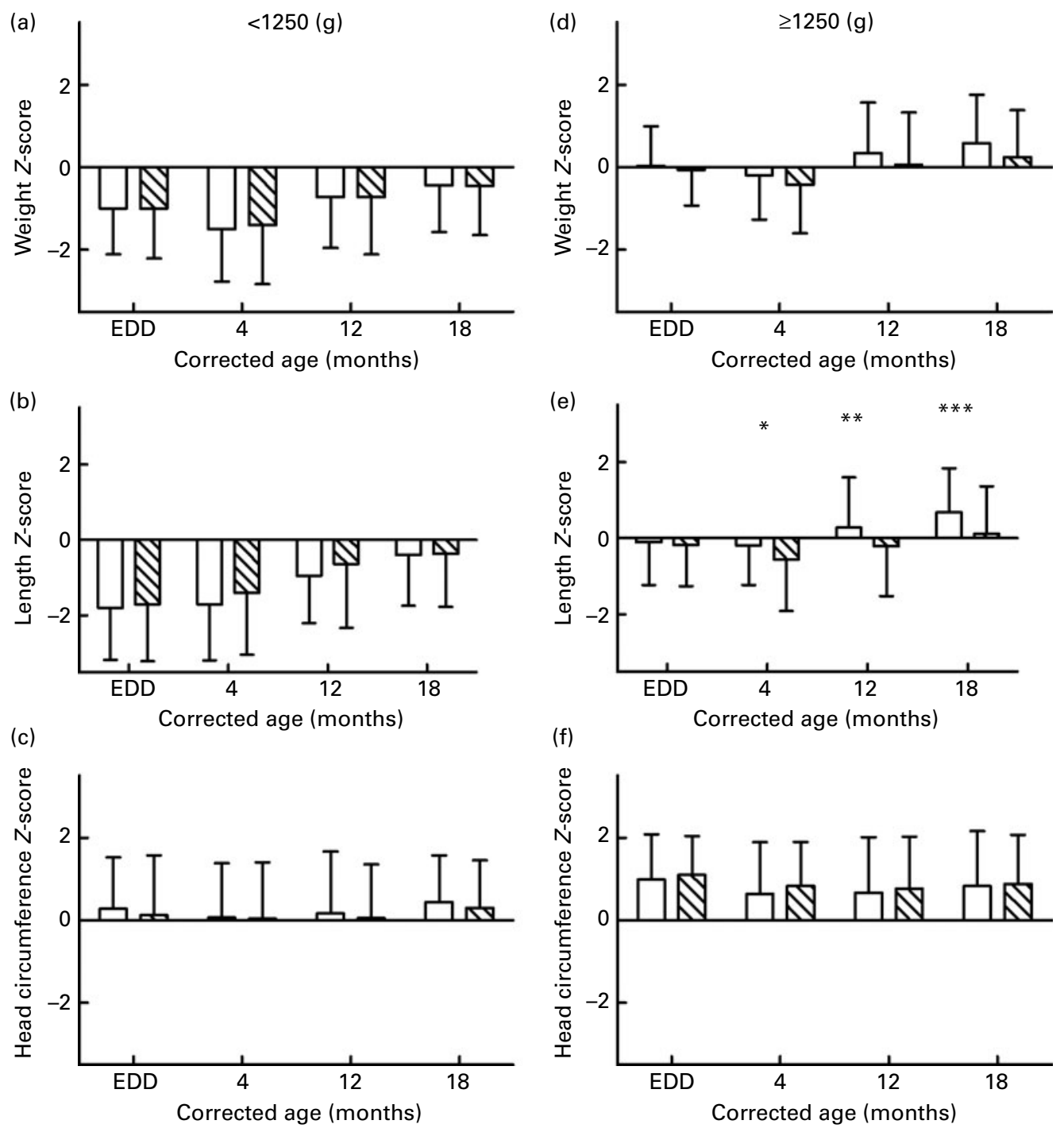

Fig. 2. (a, d) Weight, (b, e) length and (c, f) head circumference $Z$-scores by birth-weight strata $(<1250 \mathrm{~g}(\mathrm{a}-\mathrm{c})$ and $\geq 1250 \mathrm{~g}(\mathrm{~d}-\mathrm{f}))$ at expected delivery date (EDD), and at 4, 12 and 18 months corrected age. Values are means, with standard deviations represented by vertical bars. A birth weight $\times$ diet interaction for $Z$-scores existed for length $(P=0.03)$. Birth-weight strata $Z$-scores were statistically significantly different: ${ }^{\star} P=0.01,{ }^{\star \star} P=0.004,{ }^{\star \star \star} P=0.0004$. $\square$, Higher $D H A ; \mathbb{Q}$, standard DHA.

in the rate of head growth may be associated with neurodevelopmental improvement.

At the very least, our data indicate that higher DHA in the diet of pre-term infants has no negative effects on weight, length or head circumference during the first 18 months of life, despite the extreme change of LCPUFA balance in the early diet of pre-term infants. Unlike other studies, measurements of blood fatty acid status in our infants confirmed that the higher-DHA diets had resulted in a reduction in the plasma and erythrocyte membrane phospholipid AA concentrations as well as an increase in DHA and EPA in the higher DHA group compared with the standard DHA treatment ${ }^{(27)}$. Furthermore, although both groups of infants received dietary $\mathrm{AA}$, the reduction in plasma and erythrocyte phospholipid AA observed in the higher DHA group implies that there was an exchange of AA for DHA and EPA incorporation into phospholipids. The results of the present large study with a robust design refute the reports of earlier studies, which suggested that this process may be a factor influencing poor growth in pre-term infants ${ }^{(9-12)}$.

In comparison with WHO growth reference data that define ideal growth of children born at term, raised in a good environment and exclusively breast-fed, the weight and length of infants born weighing $<1250 \mathrm{~g}$ remained below the expected mean $Z$-score value of zero, although the growth of these infants improved with time. Conversely, the mean head circumference $Z$-score remained consistently above zero. In contrast, the growth of infants born weighing $\geq 1250 \mathrm{~g}$ was consistent with the WHO standard. While these data indicate that modern neonatal feeding practices result in post-term growth comparable with healthy, term infants for infants born weighing $\geq 1250 \mathrm{~g}$, there remains room for improvement with regard to feeding practices for infants born weighing $<1250 \mathrm{~g}$. 
Table 4. Milk or formula type post-intervention

(Number of infants and percentages)

\begin{tabular}{|c|c|c|c|c|c|c|c|c|c|c|c|c|}
\hline & \multicolumn{4}{|c|}{4 months corrected age } & \multicolumn{4}{|c|}{12 months corrected age } & \multicolumn{4}{|c|}{18 months corrected age } \\
\hline & \multicolumn{2}{|c|}{$\begin{array}{l}\text { Higher DHA } \\
\quad(n 306)\end{array}$} & \multicolumn{2}{|c|}{$\begin{array}{c}\text { Standard } \\
\text { DHA (n 319) }\end{array}$} & \multicolumn{2}{|c|}{$\begin{array}{l}\text { Higher DHA } \\
\quad(n \text { 295) }\end{array}$} & \multicolumn{2}{|c|}{$\begin{array}{c}\text { Standard } \\
\text { DHA }(n 319)\end{array}$} & \multicolumn{2}{|c|}{$\begin{array}{l}\text { Higher DHA } \\
\quad(n \text { 297) }\end{array}$} & \multicolumn{2}{|c|}{$\begin{array}{l}\text { Standard } \\
\text { DHA ( } n \text { 313) }\end{array}$} \\
\hline & $n$ & $\%$ & $n$ & $\%$ & $n$ & $\%$ & $n$ & $\%$ & $n$ & $\%$ & $n$ & $\%$ \\
\hline Only breast milk & 53 & $17 \cdot 3$ & 58 & $18 \cdot 2$ & 15 & $5 \cdot 1$ & 14 & 4.4 & & & & \\
\hline Only DHA-enriched formula & 116 & 37.9 & 122 & $38 \cdot 2$ & 71 & $24 \cdot 1$ & 62 & 19.4 & 13 & 4.4 & 15 & 4.8 \\
\hline Both breast milk and DHA-enriched formula & 19 & $6 \cdot 2$ & 23 & $7 \cdot 2$ & & & & & & & & \\
\hline Breast milk and formula and/or cows' milk & & & & & 12 & 4.1 & 13 & $4 \cdot 1$ & 10 & 3.4 & 8 & $2 \cdot 6$ \\
\hline Only non-DHA formula & 108 & $35 \cdot 3$ & 107 & 33.5 & 49 & $16 \cdot 6$ & 57 & 17.9 & 5 & $1 \cdot 7$ & 16 & $5 \cdot 1$ \\
\hline $\begin{array}{l}\text { Non-DHA formula and breast milk or } \\
\text { DHA-enriched formula }\end{array}$ & 10 & $3 \cdot 3$ & 9 & $2 \cdot 8$ & & & & & & & & \\
\hline Only cows' milk & & & & & 103 & 34.9 & 116 & 36.4 & 217 & 73.1 & 234 & 74.8 \\
\hline Other & \multirow{2}{*}{\multicolumn{4}{|c|}{0.98}} & 45 & $15 \cdot 3$ & 57 & 17.9 & 52 & 17.5 & 40 & $12 \cdot 8$ \\
\hline Unadjusted $P^{*}$ & & & & & \multicolumn{4}{|c|}{0.86} & \multicolumn{4}{|c|}{0.18} \\
\hline Adjusted $P^{*} \dagger$ & \multicolumn{4}{|c|}{0.98} & \multicolumn{4}{|c|}{0.85} & \multicolumn{4}{|c|}{0.17} \\
\hline
\end{tabular}

* Source of milk compared between groups using log-linear Poisson regression models.

$\dagger$ Adjusted for gestational age and sex.

Many factors influence growth including the genetic potential of each infant, the in utero and ex utero environment, including diet, infections and medical treatments. The proportion of infants fed breast milk or formula, the type of formula and the proportion of infants fed solid foods did not differ between groups in the present study; however, more detailed information on dietary intake was not collected.

In this trial of DHA supplementation, we have shown that high dietary DHA intakes, capable of suppressing AA tissue incorporation, do not adversely affect the growth of preterm infants. This observation may differ from other studies because all infants received some dietary AA or because some other studies had methodological limitations that could not exclude the possibility of bias or random error ${ }^{(9-12)}$. The modest, positive effects of the higher-DHA diet on different measures of growth observed in the birth-weight strata are worthy of further investigation, while the consistent lack of effect by infant's sex indicated that higher-DHA diets have no differential effect on growth by sex.

\section{Acknowledgements}

We thank the families, and the medical, nursing and research staff who participated in each participating centre (the Women's and Children's Hospital; Flinders Medical Centre; the King Edward Memorial Hospital; the Royal Women's Hospital; the Royal Brisbane and Women's Hospital) and the staff of the Child Nutrition Research Centre and of the Data Management and Analysis Centre, University of Adelaide, North Adelaide, Adelaide. In the past, M. M., R. A. G. and K. S. have conducted clinical trials funded by the formula industry. They have no financial interest in the production and sales of infant formula or nutritional supplements. M. M. served on scientific advisory boards for Nestlé, Fonterra, and Nutricia; R. A. G. served on scientific advisory boards for Wyeth, Fonterra and Nestlé; K. S. served on a scientific advisory board for Wyeth. Associated honoraria for M. M. and R. A. G. were paid to their institutions to support conference travel and continuing education for postgraduate students and early career researchers. The honorarium for K. S. was paid to her directly. The present study was supported by a grant from the Australian National Health and Medical Research Council (ID 250322). Treatment and placebo capsules were donated by Clover Corporation, and infant formula was donated by Mead Johnson Nutritionals and Nutricia Australasia. Research fellowships were from the National Health and Medical Research Council of Australia (M. M., R. A. G., P. G. D. and P. B. C.). None of the funding bodies or companies had any role in the study design or conduct; data collection, management, analysis or interpretation; or preparation, review or approval of the manuscript. M. M., R. A. G., A. J. M., P. G. D., K. S., P. B. C. and S. M. designed the trial. M. M., A. J. M., C. T. C., L. W. D., K. S., P. B. C., S. M. and P. R. were involved in the data collection. C. T. C., M. M., R. A. G., A. J. M., T. R. S., P. R., L. W. D., K. S., S. M. and P. G. D. conducted the data analysis and interpretation. C. T. C., M. M. and R. A. G. were responsible for drafting the manuscript; all authors critically reviewed the manuscript. Statistical analyses were conducted by T. R. S. under the supervision of P. R.

\section{References}

1. Embleton NE, Pang N \& Cooke RJ (2001) Postnatal malnutrition and growth retardation: an inevitable consequence of current recommendations in preterm infants? Pediatrics 107, 270-273.

2. Carlson SJ (1999) Actual nutrient intakes of extremely lowbirthweight infants. In Nutrition of the Very Low Birthweight Infant, pp. 221-228 [EE Ziegler, A Lucas and GE Moro, editors]. Philadelphia, PA: Lippincott Williams \& Wilkins.

3. Ehrenkranz RA, Younes N, Lemons JA, et al. (1999) Longitudinal growth of hospitalized very low birth weight infants. Pediatrics 104, 280-289.

4. Fenton TR, McMillan DD \& Sauve RS (1990) Nutrition and growth analysis of very low birth weight infants. Pediatrics 86, 378-383. 
5. Franz AR, Pohlandt F, Bode $\mathrm{H}$, et al. (2009) Intrauterine, early neonatal, and postdischarge growth and neurodevelopmental outcome at 5.4 years in extremely preterm infants after intensive neonatal nutritional support. Pediatrics $\mathbf{1 2 3}$ e101-e109.

6. Tan M, Abernethy L \& Cooke R (2008) Improving head growth in preterm infants - a randomised controlled trial II: MRI and developmental outcomes in the first year. Arch Dis Child Fetal Neonatal Ed 93, F342-F346.

7. Ehrenkranz RA (2007) Early, aggressive nutritional management for very low birth weight infants: what is the evidence? Semin Perinatol 31, 48-55.

8. Latal-Hajnal B, von Siebenthal K, Kovari H, et al. (2003) Postnatal growth in VLBW infants: significant association with neurodevelopmental outcome. [see comment]. I Pediatr 143, $163-170$.

9. Carlson SE, Werkman SH \& Tolley EA (1996) Effect of longchain $n$-3 fatty acid supplementation on visual acuity and growth of preterm infants with and without bronchopulmonary dysplasia. Am J Clin Nutr 63, 687-697.

10. Ryan AS, Montalto MB, Groh-Wargo S, et al. (1999) Effect of DHA-containing formula on growth of preterm infants to 59 weeks postmenstrual age. Am J Hum Biol 11, 457-467.

11. Carlson SE, Cooke RJ, Werkman SH, et al. (1992) First year growth of preterm infants fed standard compared to marine oil $n-3$ supplemented formula. Lipids 27, 901-907.

12. Carlson SE, Werkman SH, Peeples JM, et al. (1993) Arachidonic acid status correlates with first year growth in preterm infants. Proc Natl Acad Sci U S A 90, 1073-1077.

13. Clandinin MT, Van Aerde JE, Merkel KL, et al. (2005) Growth and development of preterm infants fed infant formulas containing docosahexaenoic acid and arachidonic acid. J Pediatr 146, 461-468.

14. Innis SM, Adamkin DH, Hall RT, et al. (2002) Docosahexaenoic acid and arachidonic acid enhance growth with no adverse effects in preterm infants fed formula. $J$ Pediatr 140, 547-554.

15. O'Connor DL, Hall R, Adamkin D, et al. (2001) Growth and development in preterm infants fed long-chain polyunsaturated fatty acids: a prospective, randomized controlled trial. Pediatrics 108, 359-371.

16. Vanderhoof J, Gross S, Hegyi T, et al. (1999) Evaluation of a long-chain polyunsaturated fatty acid supplemented formula on growth, tolerance, and plasma lipids in preterm infants up to 48 weeks postconceptional age. J Pediatr Gastroenterol Nutr 29, 318-326.

17. Clandinin MT, Van Aerde JE, Parrott A, et al. (1997) Assessment of the efficacious dose of arachidonic and docosahexaenoic acids in preterm infant formulas: fatty acid composition of erythrocytemembrane lipids. Pediatr Res 42, 819-825.

18. Stier C, Hess M, Watzer B, et al. (1997) Prostanoid formation during feeding of a preterm formula with long-chain polyunsaturated fatty acids in healthy preterm infants during the first weeks of life. Pediatr Res 42, 509-513.

19. Fewtrell MS, Morley R, Abbott RA, et al. (2002) Double-blind, randomized trial of long-chain polyunsaturated fatty acid supplementation in formula fed to preterm infants. [see comment]. Pediatrics 110, 73-82.

20. Simmer K, Schulzke SM \& Patole S (2008) Long chain polyunsaturated fatty acid supplementation in preterm infants. The Cochrane Database of Systematic Reviews 2008, issue 1, CD000375. http://www.mrw.interscience. wiley.com/cochrane/clsysrev/articles/CD000375/frame.html.

21. Rosenfeld E, Beyerlein A, Hadders-Algra M, et al. (2009) IPD meta-analysis shows no effect of LC-PUFA supplementation on infant growth at 18 months. Acta Paediatrica 98, 91-97.

22. Makrides M, Gibson RA, McPhee AJ, et al. (2009) Neurodevelopmental outcomes of preterm infants fed high-dose docosahexaenoic acid: a randomized controlled trial. JAMA 301, 175-182.

23. WHO Multicentre Growth Reference Study Group (2006) WHO Child Growth Standards based on length/height, weight and age. Acta Paediatr Suppl 450, 76-85.

24. WHO (2009) Anthro for Personal Computers, Version 3: Software for Assessing Growth and Development of the World's Children. Geneva: WHO. http://www.who.int/childgrowth/ software/en.

25. Kan E, Roberts G, Anderson PJ, et al. (2008) The association of growth impairment with neurodevelopmental outcome at eight years of age in very preterm children. Early Hum Dev 84, 409-416.

26. Ehrenkranz RA, Dusick AM, Vohr BR, et al. (2006) Growth in the neonatal intensive care unit influences neurodevelopmental and growth outcomes of extremely low birth weight infants. Pediatrics 117, 1253-1261.

27. Smithers LG, Gibson RA, McPhee A, et al. (2008) Effect of two doses of docosahexaenoic acid (DHA) in the diet of preterm infants on infant fatty acid status: results from the DINO trial. Prostaglandins Leukot Essent Fatty Acids 79, 141-146.

28. Gibson RA, Neumann MA \& Makrides M (1997) Effect of increasing breast milk docosahexaenoic acid on plasma and erythrocyte phospholipid fatty acids and neural indices of exclusively breast fed infants. Eur J Clin Nutr 51, $578-584$ 